\title{
Comparison of predicted body fat percentage from anthropometric methods and from impedance in university students
}

\author{
${\text { Marta } \text { Arroyo }^{1 *} \text {, Ana M. Rocandio }}^{1}$, Laura Ansotegui ${ }^{1}$, Hector Herrera ${ }^{2}$, Itziar Salces ${ }^{2}$ and \\ Esther Rebato ${ }^{2}$ \\ ${ }^{1}$ Department of Nutrition and Food Science, Faculty of Pharmacy, University of the Basque Country, Vitoria-Gasteiz, Spain \\ ${ }^{2}$ Department of Genetics, Physical Anthropology and Animal Physiology, Faculty of Sciences, \\ University of the Basque Country, Bilbao, Spain
}

(Received 12 February 2004 - Revised 29 July 2004 - Accepted 3 August 2004)

\begin{abstract}
The objective of the present study was to compare different methods for evaluating body fat percentage (BF\%) (anthropometric methods and bioelectrical impedance analysis) in university students. Subjects were 653 healthy students whose mean age, body height, body weight and BMI were 21.1 (SD 2.5) years, 166.0 (SD 8.4) cm, 62.8 (SD 11.0) kg and $22.7(\mathrm{SD} 3.1) \mathrm{kg} / \mathrm{m}^{2}$, respectively. Results showed that BMI is a poor predictor of body fatness since the sensitivity was low in comparison with the reference method (Siri equation). The lowest values of BF\% were obtained using the reference method (Siri equation) (21.8 (SD 6.8) \%). The two methods with the highest agreement were Siri and Lean (mean difference, -0.5 ), followed by Brozek (mean difference, -1.4 ) and Deurenberg (mean difference, -1.5). The largest mean difference for BF\% was between Siri and impedance (-4.5). Although the methods and/or equations used in the present study have been commonly utilised to estimate BF\% in young adults, the results must be interpreted with caution in the diagnosis and monitoring of overweight and obesity.
\end{abstract}

Body fat: Bioelectrical impedance analysis: Anthropometry: University students

Given the rising incidence of obesity in the young population of Western countries and, therefore, the importance of measuring body fat, there has been a resurgence of interest in the evaluation of different body composition methods (Gruber et al. 2001; Kitano et al. 2001).

The World Health Organization (1995, 1998) defines overweight and obesity at BMI cut-off points of 25 and $30 \mathrm{~kg} / \mathrm{m}^{2}$, respectively, in adult populations. However, there is increasing evidence that these cut-off values are not valid for all populations (Luke et al. 1997; Deurenberg et al. 1998; Deurenberg-Yap et al. 2000) as the relationship between BMI and body fat percentage $(\mathrm{BF} \%)$ differs between population groups. Furthermore, it is the amount of body fat, rather than the amount of excess weight, that determines the health risks of obesity (World Health Organization, 1998). This explains the increasing interest of scientists and the general public in body fat measurements.

Although there are several methods to estimate $\mathrm{BF} \%$, there is no 'gold standard' for both epidemiological studies and personal use. However, some scientific societies such as the Spanish Society for Obesity Research recommend the
Siri equation, based on anthropometric measures, to determine BF\% (SEEDO, 1996). There are other more accurate methods, for example, the underwater weighing method or dual-energy X-ray absorptiometry, but their cost and complexity limit widespread use (Bray et al. 1998).

Comparisons between body composition methods have been made in healthy populations of both children (Ellis, 1996; Gutin et al. 1996; Treuth et al. 2001; Fors et al. 2002) and adults (Heymsfield et al. 1990; Wellens et al. 1994). Although there is literature on the differences in body composition between university athletes and nonathletic subjects (Emslander et al. 1998; Mitsuzono \& Komiya, 1991), as far as we know, no study has compared the estimates of $\mathrm{BF} \%$ by using different methods on university students.

Therefore, the purpose of the present study was to compare estimates of $\mathrm{BF} \%$ by different methods (anthropometry and bioelectrical impedance analysis) in university students. Additionally, we investigated the association between $\mathrm{BF} \%$ and BMI to evaluate the screening performance of the BMI focused on individual preventive medicine.

\footnotetext{
Abbreviations: $\mathrm{BF} \%$, body fat percentage; $\mathrm{BF} \%_{\mathrm{BROZEK}}$, body fat percentage predicted by Brozek equation; BF\% ${ }_{\mathrm{DEURENBERG}}$, body fat percentage predicted by Deurenberg equation; BF\% $\%_{\text {IMP }}$, body fat percentage evaluated by impedance; BF\% $\%_{\text {LEAN }}$, body fat percentage predicted by Lean equation; BF\% $\%_{\text {SIRI }}$, body fat percentage predicted by Siri equation; WHR, waist:hip ratio.

* Corresponding author: Dr Marta Arroyo, fax +34 945 013014, email knparizm@vc.ehu.es
} 


\section{Methods}

\section{Subjects}

A cross-sectional study of students from the University of the Basque Country (Spain) was carried out. The sample was composed of 653 individuals (190 males and 463 females) aged 18-30 years and recruited from different degrees. The sample size was considered as representative according to the estimations performed by means of the formula by Martin \& De Dios (1993) and according to the deviation of $\mathrm{BF} \%$ from a previous study in populations of the Basque Community (Servicio Central de Publicaciones del Gobierno Vasco, 1994). A stratified recruitment design was used according to demographic data (age, sex and number of students per campus).

The aim of the present study and the kind of measurements were explained to the participants, who gave their informed written consent. The experimental protocol was approved by the University Ethical Committee on Human Research.

All measurements were done on the same visit at the nutrition and physical anthropology laboratories (University of the Basque Country) and at least $3 \mathrm{~h}$ after a meal (including drink). Apart from these measurements, the subjects were requested to refrain from strenuous exercise $12 \mathrm{~h}$ before the measurements and they were asked to empty their bladders before the evaluation. Females were not measured during their menstrual period.

\section{Anthropometric measurements}

A well-trained anthropometrist performed all the measurements. Body weight was measured to $0 \cdot 1 \mathrm{~kg}$ using a standard beam balance (Añó-Sayol ${ }^{\circledR}$; Atlántida, Añó Sayol, Barcelona, Spain). Height was measured to the nearest $1 \mathrm{~mm}$ using a Harpenden stadiometer (Holtain Ltd, Crymych, Wales, UK). With these data we calculated the BMI (weight $(\mathrm{kg}) /$ height $\left.(\mathrm{m})^{2}\right)$. The skinfold thicknesses (biceps, triceps, subscapular and supra-iliac) were measured in duplicate on the left side of the body to the nearest $0.1 \mathrm{~mm}$ with a Holtain skinfold caliper (Holtain Ltd).

Circumferences of the waist and hip were also taken in duplicate to the nearest $1 \mathrm{~mm}$ with a tape measure. BF\% was calculated using some prediction equations from the literature: Siri (1961), Brozek (Brozek et al. 1963), Deurenberg (Deurenberg et al. 1991) and Lean (Lean et al. 1996) equations (BF\% $\%_{\text {SIRI }}, \mathrm{BF} \%_{\text {BROZEK, }}$ BF\% $\%_{\text {DEURENBERG }}$ and BF\% $\%_{\text {LEAN }}$ respectively). In the Siri and Brozek equations, density was predicted using Durnin \& Womersley's formula (Durnin \& Womersley, 1974).

The subjects were classified according to BF\% using the criteria of Bray et al. (1998) for the classification of obesity. BMI was classified according to the categories of obesity and overweight of the World Health Organization (1998). Additionally, we evaluated the regional adiposity using the waist:hip ratio (WHR) and the waist circumference. The volunteers were classified at risk according to Heymsfield et al. (1998) and National Institutes of Health criteria (National Institutes of Health, National Heart, Lung and Blood Institute, 1999), respectively. The descriptive statistics of the anthropometric traits and the age of the subjects are displayed in Table 1.

\section{Bioelectrical impedance analysis}

Bioelectrical impedance analysis measurements were performed using a tetrapolar multi-frequency impedanciometer (MediSystem-SanoCare Human Systems S.L., Madrid, Spain). All measurements were performed in accordance with the manufacturer's instruction manual. $\mathrm{BF} \%$ evaluated by impedance (BF\% $\mathrm{IMP})$ was estimated using Lohman's formula (Lohman, 1992) based on preentered personal particulars (weight, height, age and sex) and impedance value.

\section{Statistical analysis}

Data were gathered using SPSS 10.0 (SPSS Inc., Chicago, IL, USA) with significance set at $P<0.05$ and presented as mean values and standard deviations. Bland-Altman analysis (Bland \& Altman, 1986) was used to test for bias (mean difference) and limits of agreement among all the methods. Measures of BF\% from the Siri equation were used as the reference method, according to the recommendation of the Spanish Society for Obesity Research (SEEDO, 1996). Sensitivity, specificity and predictive values were calculated to evaluate the classification of obesity using the BMI as compared with the reference method. In the present study, test sensitivity was the proportion of obesity cases, as diagnosed by the reference method, found by BMI. Specificity refers to the proportion of subjects identified by the reference method as non-obese and that BMI classified correctly. The positive predictive value is the probability that a student classified as obese by BMI actually is found to be so by the reference method. The negative predictive value gives us the probability that a subject classified as non-obese by BMI is also defined as non-obese by the reference method.

\section{Results}

\section{Subjects' characteristics}

In total, 653 subjects participated in the present study, the 463 females ranging in age from 18 to 30 years, in BMI from 16.7 to $34.2 \mathrm{~kg} / \mathrm{m}^{2}$ and in $\mathrm{BF} \%_{\text {SIRI }}$ from 12 to $41 \%$. The 190 males ranged in age from 18 to 29 years, in BMI from 17.5 to $38.6 \mathrm{~kg} / \mathrm{m}^{2}$ and in $\mathrm{BF} \%_{\text {SIRI }}$ from 7 to $31 \%$. The characteristics of the subjects are given in Table 1. An acceptable BMI existed for $75.7 \%$ of the subjects and $3.8 \%$ of the total sample were classified as low weight (one male and twenty-four females). Significant differences between the sexes were found for all parameters $(P<0 \cdot 01)$, except for subscapular skinfold.

According to $\mathrm{BF} \%_{\text {SIRI }}, 6 \cdot 1 \%$ of the subjects were classified as obese (seven males and thirty-three females) and $9.7 \%$ as overweight (twenty-four males and thirty-nine females). However, according to the BMI classification, $2.5 \%$ were obese (eight males and eight females) and $17.2 \%$ of the total sample were overweight (forty-five males and sixty-seven females).

The results showed the strongest specificity (1) and positive prediction (1) of BMI in the identification of obese subjects $\left(\right.$ BMI $\geq 30.0 \mathrm{~kg} / \mathrm{m}^{2}$ ). However, the sensitivity was low $(0.4)$ and negative predictive value was 0.96 . 
Table 1. Anthropometric data

(Mean values and standard deviations)

\begin{tabular}{|c|c|c|c|c|c|c|}
\hline & \multicolumn{2}{|c|}{ Total $(n 653)$} & \multicolumn{2}{|c|}{ Males $(n 190)$} & \multicolumn{2}{|c|}{$\begin{array}{c}\text { Females } \\
(n \text { 463) }\end{array}$} \\
\hline & Mean & SD & Mean & SD & Mean & SD \\
\hline Age (years) & $21 \cdot 1$ & 2.5 & $21 \cdot 2$ & $2 \cdot 3$ & $21 \cdot 0$ & $2 \cdot 6$ \\
\hline Weight $(\mathrm{kg})$ & $62 \cdot 8$ & $11 \cdot 0$ & 73.1 & 9.9 & $58 \cdot 6$ & 8.4 \\
\hline Height $(\mathrm{cm})$ & $166 \cdot 0$ & 8.4 & $175 \cdot 2$ & $6 \cdot 8$ & $162 \cdot 3$ & $5 \cdot 8$ \\
\hline BMI $\left(\mathrm{kg} / \mathrm{m}^{2}\right)$ & $22 \cdot 7$ & 3.1 & 23.9 & 3.0 & $22 \cdot 2$ & $3 \cdot 0$ \\
\hline Waist circumference $(\mathrm{cm})$ & 80.5 & $7 \cdot 7$ & 83.4 & 8.0 & $79 \cdot 4$ & $7 \cdot 2$ \\
\hline Hip circumference $(\mathrm{cm})$ & 94.5 & 6.9 & $95 \cdot 7$ & $6 \cdot 8$ & $94 \cdot 1$ & $6 \cdot 9$ \\
\hline WHR & 0.9 & 0.1 & 0.9 & 0.1 & 0.8 & $0 \cdot 1$ \\
\hline \multicolumn{7}{|l|}{ Skinfolds (mm) } \\
\hline Triceps & $16 \cdot 6$ & $6 \cdot 3$ & $11 \cdot 0$ & $5 \cdot 1$ & $18 \cdot 9$ & $5 \cdot 3$ \\
\hline Biceps & $9 \cdot 6$ & 4.5 & $7 \cdot 0$ & 3.7 & $10 \cdot 7$ & 4.4 \\
\hline Subscapular & $14 \cdot 0$ & $5 \cdot 6$ & 13.5 & $5 \cdot 7$ & $14 \cdot 2$ & $5 \cdot 6$ \\
\hline Supra-iliac & $16 \cdot 3$ & $7 \cdot 6$ & $14 \cdot 8$ & $7 \cdot 6$ & $16 \cdot 9$ & 7.5 \\
\hline Total of four skinfolds $(\mathrm{mm})$ & $56 \cdot 5$ & $20 \cdot 8$ & $46 \cdot 4$ & $19 \cdot 7$ & $60 \cdot 6$ & $19 \cdot 8$ \\
\hline
\end{tabular}

WHR, waist:hip ratio.

In the total sample, $3.7 \%$ of the subjects would be falsely classified as non-obese with BMI.

According to the waist circumference, $9.8 \%$ of the total were classified as at risk $(3.7 \%$ of the males and $12.3 \%$ of the females). Additionally, according to the WHR, $31.2 \%$ of the total sample were classified as at risk $(2.1 \%$ of the males and $43.2 \%$ of the females).

\section{Comparisons of the body fat assessment methods}

For the overall female population BF\% ${ }_{\text {BROZEK }}(26 \cdot 2$ (SD 4.2) $),$ BF\% $\%_{\text {DEURENBERG }}\left(26 \cdot 0\right.$ (SD 3.3)), BF\% $\%_{\text {LEAN }}(25 \cdot 2$ (SD 4.0)) and $\mathrm{BF} \%_{\mathrm{IMP}}(29.0$ (SD 4.1)) were significantly different from BF\% $\%_{\text {SIRI }}(24.3$ (SD 5.8)) $(P<0.001)$. For the overall male population $\mathrm{BF} \%_{\mathrm{BROZEK}}(16 \cdot 1$ (SD $4 \cdot 4)$ ), BF\% $\%_{\text {DEURENBERG }}(16.7$ (SD 3.6)) and BF\% IMP (20.0 (SD $5 \cdot 3)$ ) were significantly different from BF\% $\%_{\text {SIRI }}(15.9$ (SD 5.0)) $(P<0 \cdot 01)$.

The lowest values of BF\% were obtained with Siri $(21.8$ (SD 6.8) \%), followed by Lean (22.3 (SD 6.2) \%), Brozek (23.3 (SD 6.3) \%) and Deurenberg (23.3 (SD 5.4) \%), with impedance giving the highest value of percentage fat $(26.4(\operatorname{SD~} 6 \cdot 1) \%)$. The percentage fat mass from the Lean and Deurenberg equations suggested that 6.9 and $10.0 \%$ were overweight or obese, respectively. BF\% from the Brozek equation and from impedance indicated a high tendency towards overweight or obesity (15.6 and $36.5 \%$, respectively).

When obesity was defined using the BF\% $\%_{\text {SIRI }}$ in males, Deurenberg and Brozek equations underestimated BF\% at higher values of body fat $(\mathrm{BF} \% \geq 25)\left(\mathrm{BF} \%_{\text {SIRI }}, 28 \cdot 1\right.$ (SD 2.6); BF\% $\%_{\text {DEURENBERG, }} 25.6$ (SD 4.3); BF\% $\%_{\text {BROZEK, }} 26.6$ (SD 2.2)) (in all cases, $P<0 \cdot 05$ ). In males, the Lean, Deurenberg and Brozek formulas underestimated $\mathrm{BF} \%$ at higher values of body fat $(\mathrm{BF} \% \geq 33)\left(\mathrm{BF} \%_{\mathrm{SIRI}}, 35 \cdot 4\right.$ (SD 2.1); BF\% $\%_{\text {LEAN }}, 30.3$ (SD 3.9); BF\% $\%_{\text {DEURENBERG }} 31.7$ (SD 3.2); BF\% $\%_{\text {BROZEK }}, 34 \cdot 0$ (SD 1.7)) (in all cases, $P<0.001$ ).

\section{Limits of agreement}

The biases (mean differences) for BF\% and the limits of agreement between the five methods are shown in Table 2. For BF\%, the two methods with the highest agreement were Siri and Lean, the mean difference being

Table 2. Assessment of agreement between the Siri (1961) equation and the other methods used to estimate body fat percentage

\begin{tabular}{|c|c|c|c|c|c|c|}
\hline \multirow[b]{2}{*}{ Comparison } & \multirow[b]{2}{*}{ Mean difference* } & \multirow[b]{2}{*}{$95 \% \mathrm{Cl}$} & \multirow[b]{2}{*}{$\mathrm{SD}^{*} \dagger$} & \multirow[b]{2}{*}{$\mathrm{Cl}^{*}$} & \multicolumn{2}{|c|}{$\begin{array}{l}\text { Limits of agree- } \\
\text { ment }^{\star}\end{array}$} \\
\hline & & & & & Lower & Upper \\
\hline Siri-Brozek $\ddagger$ & -1.4 & $-1 \cdot 7,-1 \cdot 2$ & 2.9 & $11 \cdot 4$ & $-7 \cdot 2$ & 4.3 \\
\hline Siri-Deurenberg§ & -1.5 & $-1 \cdot 8,-1 \cdot 2$ & 4.2 & $16 \cdot 8$ & -9.9 & $6 \cdot 9$ \\
\hline Siri-Leanף & -0.5 & $-0.9,-0.1$ & 4.8 & $19 \cdot 3$ & $-10 \cdot 2$ & 9.1 \\
\hline Siri-IMP & -4.5 & $-4 \cdot 8,-4 \cdot 1$ & $4 \cdot 3$ & $17 \cdot 2$ & $-13 \cdot 1$ & $4 \cdot 2$ \\
\hline
\end{tabular}

IMP, impedance analysis.

*Bland-Altman method.

† SD of difference.

$\ddagger$ Brozek et al. (1963).

$\S$ Deurenberg et al. (1991)

q Lean et al. (1996). 
$-0.5(95 \%$ CI $-0.9,-0 \cdot 1)$. However, the largest mean difference for $\mathrm{BF} \%$ was between Siri and impedance $(-4.5)$. The Bland-Altman plots for BF\% illustrate the mean differences and the fairly large limits of agreement by different methods (Fig. 1).

\section{Discussion}

Despite a relatively low mean BMI $\left(22.7(\mathrm{SD} 3 \cdot 1) \mathrm{kg} / \mathrm{m}^{2}\right)$, body fat levels determined by the Siri equation were classified in $6.1 \%$ of the subjects as obese and in $9.7 \%$ as overweight. The percentages classified as overweight and obese were lower than those reported in previous studies (Lowry et al. 2000; Huang et al. 2003).

The results showed that the BMI is a poor predictor of body fatness, since the sensitivity was low in comparison with the reference method (Siri equation). It was shown in earlier studies (Garn et al. 1986; Smalley et al. 1990; Hannan et al. 1995; Deurenberg et al. 2001) that BMI has considerable limitations in predicting an individual's $\mathrm{BF} \%$. This is why the body composition measurement is
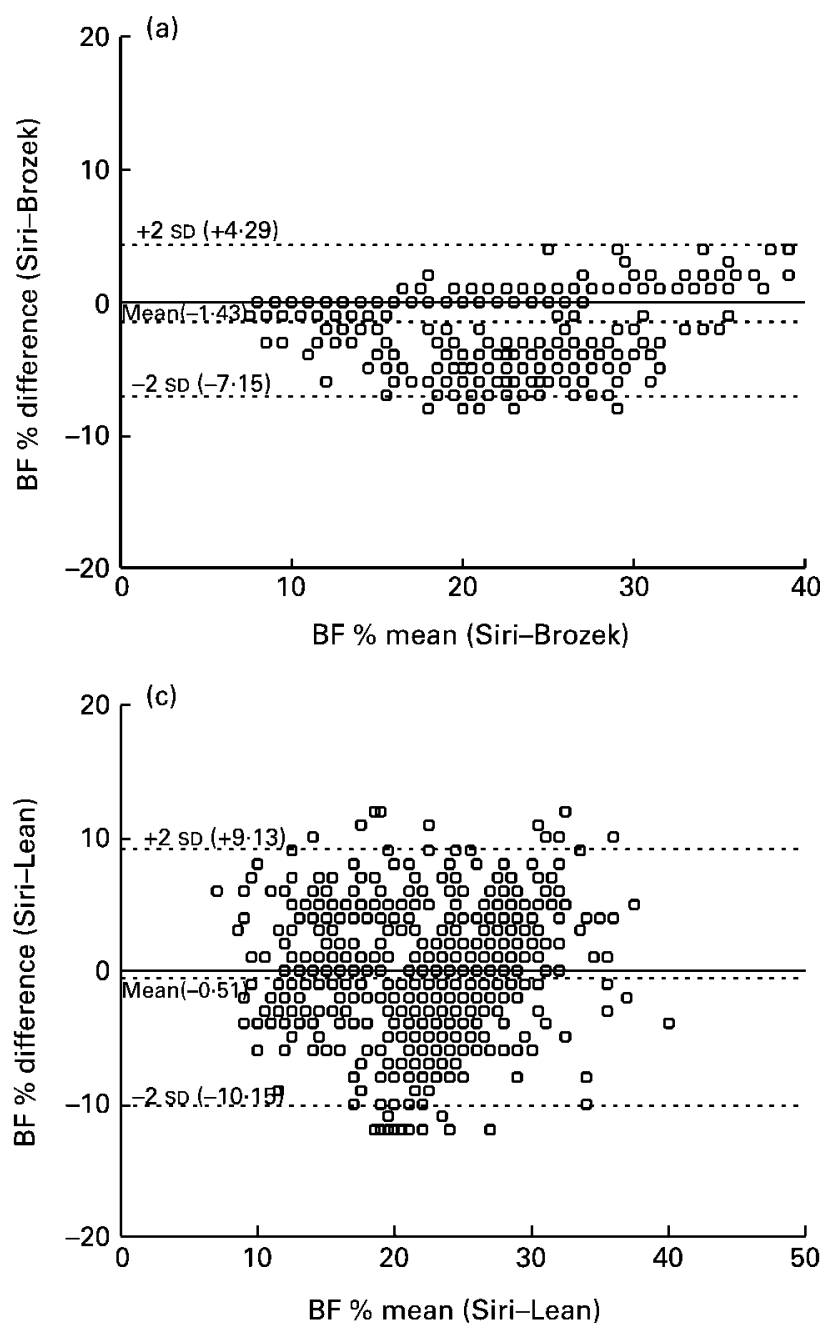

necessary for the individual evaluation of fatness focused on preventive medicine.

In females, $5.6 \%$ would be falsely classified as nonobese according to their BMI and in males $1.1 \%$ would be falsely classified as obese using this weight-height index. Underprediction of obesity might be considered as a greater error than an equal-magnitude overprediction would be. Classifying an individual as lean, when in fact the individual is truly obese regarding his or her body fatness, may put this individual at risk from diseases associated with obesity and, potentially, delay any possible beneficial therapy.

The different forms of obesity (android and gynoid) and the different health risks associated with them are other considerations to take into account. Recent studies indicate that abdominal obesity is more strongly associated with obesity-related health problems than is adiposity measured by BMI (Booth et al. 2000). In the present study, 9.8 and $31.2 \%$ of the students were classified at risk according to the waist circumference and WHR, respectively. We have observed similar results with the Siri equation, waist circumference and WHR. Concerning these results,
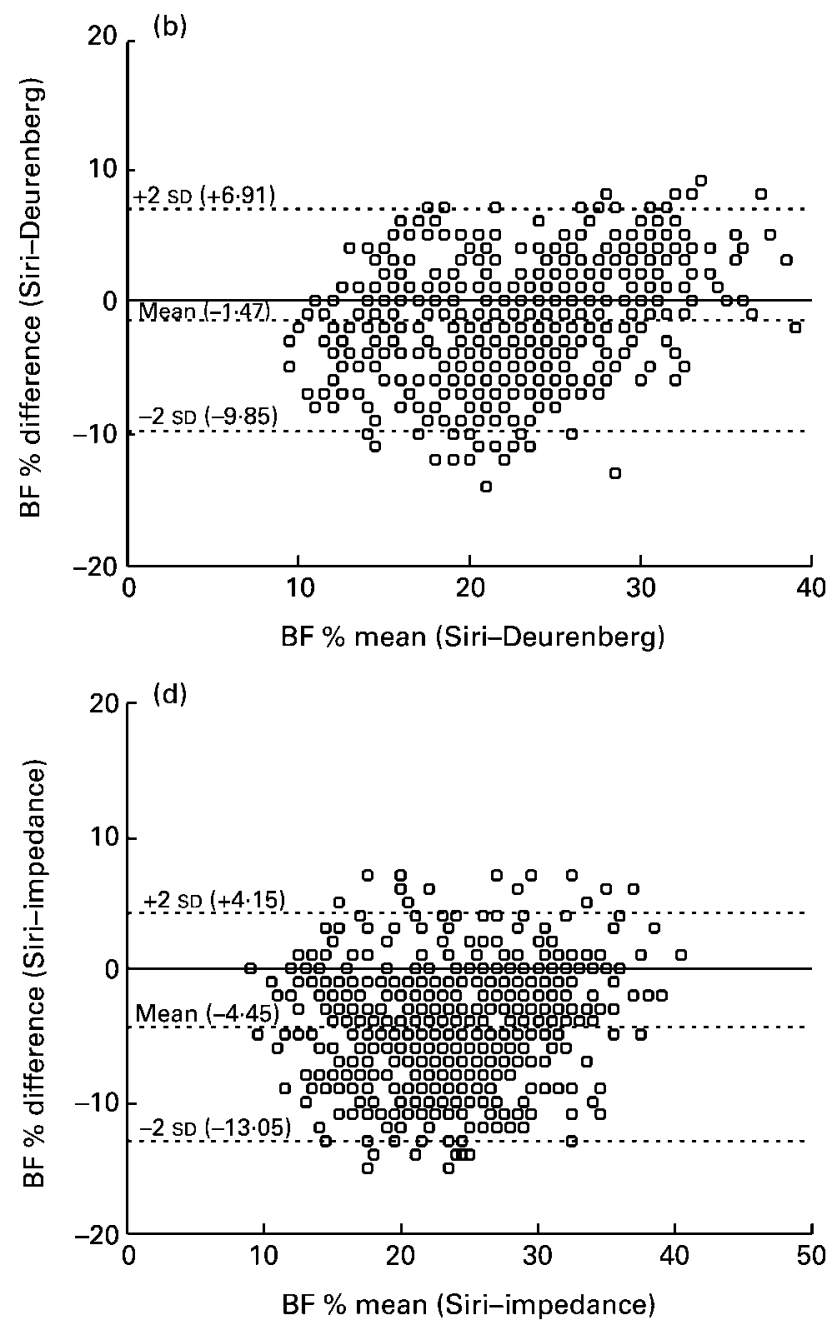

Fig. 1. Bland-Altman plots to compare body fat percentage (BF\%) measured by different methods. (a) Comparison of Siri (1961) and Brozek et al. (1963) (Siri-Brozek); (b) comparison of Siri (1961) and Deurenberg et al. (1991) (Siri-Deurenberg); (c) comparison of Siri (1961) and Lean et al. (1996) (Siri-Lean); (d) comparison of Siri (1961) and bioelectrical impedance analysis (Siri-impedance). 
Taylor et al. (1998) observed that waist circumference was better than the WHR when screening for regional fat distribution using dual-energy X-ray absorptiometry as the reference.

All methods were significantly different for BF\%. When considering the bias among methods for BF\%, the Siri and Lean equations were the most similar. Not surprisingly, the equation that included the waist circumference (one of the most labile sites of fat deposition) displayed the highest agreement with Siri. However, this situation is somewhat confusing since we registered the highest CI when we compared Siri and Lean. Brozek had the narrowest limits of agreement relative to the reference $(-7.2,4.3 \%)$ of the $\mathrm{BF} \%$. It should be noted that Siri and Brozek are the two equations that include $\log \Sigma 4$ skinfolds. Measurements of skinfold thickness are an easy method of assessing BF\% and believed to be reasonably precise (Hannan et al. 1995; Sarria et al. 1998).

If an error of 4 percentage points $\mathrm{BF} \%$ is considered as reasonable (Lohman, 1992), in line with the standard error of estimation of most prediction equations (Durnin \& Womersley, 1974; Deurenberg et al. 1991; Gallagher et al. 1996), the present results of mean differences between Siri and impedance are acceptable. However, the CI between Siri and impedance was larger. This is to be expected as the impedance formula uses additional information, which, theoretically, enables us to distinguish between fat and fat-free mass. Bioimpedance analysis would overestimate $\mathrm{BF} \%$, so should be used with caution in the diagnosis of obesity in this population.

Different findings have been observed by McNeill et al. (1991) in adults and by Deurenberg et al. (1989) in children. McNeill et al. (1991) observed the skinfold thickness method to be as good as bioelectrical impedance in lean and overweight groups of women. In children, Deurenberg et al. (1989) published a study in which prediction formulas for body composition from body impedance were presented; in pre-pubescent boys and girls $\mathrm{BF} \%$ could be predicted with an error of about $4.2 \%$, which is comparable with the prediction error for the assessment of BF\% from skinfold thickness (Deurenberg et al. 1990).

The prediction of BF\% from BMI, age and sex (Deurenberg equation) assumes that, when BMI increases over a certain threshold, the excess value is due to body fat in a fixed part. This assumption certainly has its flaws and it explains why the prediction formula generally underestimates $\mathrm{BF} \%$ at high values of body fat.

Nevertheless, the four methods were different from the Siri equation and, in many cases, the limits of agreement may be considered as high. Similar findings have been observed in children (Parker et al. 2003) and in older adults (Aghdassi et al. 2001; Barbosa et al. 2001). We found that measurements of body fat may depend on many factors, and the different methods studied are generally not directly interchangeable.

Although the methods and/or equations used in the present study have commonly been used to estimate $\mathrm{BF} \%$ in young adults, they must not be used as a standard method. Each method has limitations and the comparison can be useful for an interpretation of results. More comparative studies should be conducted to get a better insight into the generalisation of prediction methods and formulas. Individual results and classifications have to be interpreted with caution in the diagnosis and monitoring of overweight and obesity.

\section{Acknowledgements}

The present study was supported by the University of the Basque Country (UPV 00154.310-E-13972/2001 and UPV 00101.125-15283/2003). We would like to thank the students who participated in the present study.

\section{References}

Aghdassi E, Tam C, Liu B, McArthur M, McGeer A, Simor A \& Allard JP (2001) Body fat of older adult subjects calculated from bioelectrical impedance versus anthropometry correlated but did not agree. J Am Diet Assoc 101, 1209-1212.

Barbosa AR, Santarem JM, Jacob Filho W, Meirelles ES \& Marucci JM (2001) Comparison of body fat using anthropometry, bioelectrical impedance and DEXA in elderly women. Arch Latinoam Nutr 51, 49-56.

Bland JM \& Altman DG (1986) Statistical methods for assessing agreement between two methods of clinical measurement. Lancet i, 307-310.

Booth ML, Hunter C, Gore CJ, Bauman A \& Owen N (2000) The relationship between body mass index and waist circumference: implications for estimates of the population prevalence of overweight. Int J Obes Relat Metab Disord 24, 1058-1061.

Bray G, Bouchard C \& James P (1998) Definitions and proposed current classifications of obesity. In Handbook of Obesity, pp. 31-40 [G Bray, C Bouchard and P James, editors]. New York: Marcel Dekker.

Brozek J, Grande F, Anderson JT \& Keys A (1963) Densitometric analysis of body composition: revision of some quantitative assumptions. Ann N Y Acad Sci 110, 113-140.

Deurenberg P, Andreoli A, Borg P, Kukkonen-Harjula K, de Lorenzo A, van Marken Lichtenbelt WD, Testolin G, Vigano R \& Vollaard N (2001) The validity of predicted body fat percentage from body mass index and from impedance in samples of five European populations. Eur J Clin Nutr 55, 973-979.

Deurenberg P, Pieters JJ \& Hautvast JG (1990) The assessment of the body fat percentage by skinfold thickness measurements in childhood and young adolescence. Br J Nutr 63, 293-303.

Deurenberg P, van-der-Kooy K, Paling A \& Withagen P (1989) The assessment of the body composition in 8-11 year-old children by bioelectrical impedance. Eur J Clin Nutr 43, 623-629.

Deurenberg P, Weststrate JA \& Seidell JC (1991) Body mass index as a measure of body fatness: age and sex specific prediction formulas. Br J Nutr 65, 105-114.

Deurenberg P, Yap M \& van Staveren WA (1998) Body mass index and percent body fat: a meta analysis among different ethnic groups. Int J Obes Relat Metab Disord 22, 1164-1171.

Deurenberg-Yap M, Schmidt G, van Staveren WA \& Deurenberg $\mathrm{P}$ (2000) The paradox of low body mass index and high body fat percent among Chinese, Malays and Indians in Singapore. Int J Obes Relat Metab Disord 24, 1011-1017.

Durnin JVGA \& Womersley J (1974) Body fat assessed from total body density and its estimation from skinfold thickness: measurements on 481 men and women aged from 16 to 72 years. Br J Nutr 32, 77-97.

Ellis KJ (1996) Measuring body fatness in children and young adults: comparison of bioelectrical impedance analysis, 
total body electrical conductivity, and dual-energy X-ray absorptiometry. Int J Obes Relat Metab Disord 20, 866-873.

Emslander HC, Sinaki M, Muhs JM, Chao EY, Wahner HW, Bryant SC, Riggs BL \& Eastell R (1998) Bone mass and muscle strength in female college athletes (runners and swimmers). Mayo Clin Proc 73, 1151-1160.

Fors H, Gelander L, Bjarnason R, Albertsson-Wikland K \& Bosaeus I (2002) Body composition, as assessed by bioelectrical impedance spectroscopy and dual-energy X-ray absorptiometry, in a healthy pediatric population. Acta Paediatr 91, 755-760.

Gallagher D, Visser M, Sepulveda D, Pierson RN, Harris T \& Heymsfield SB (1996) How useful is body mass index for comparison of body fatness across age, sex and ethnic groups? Am J Epidemiol 143, 228-239.

Garn SM, Leonard WR \& Hawthorne VM (1986) Three limitations of the body mass index. Am J Clin Nutr 44, 996-997.

Gruber AJ, Pope HG Jr, Lalonde JK \& Hudson JI (2001) Why do young women diet? The roles of body fat, body perception, and body ideal. J Clin Psychiatry 62, 609-611.

Gutin B, Litaker M, Islam S, Manos T, Smith C \& Treiber F (1996) Body-composition measurement in 9-11 y old children by dual-energy X-ray absorptiometry, skinfold-thickness measurements, and bioimpedance analysis. Am J Clin Nutr 63, 287-292.

Hannan WJ, Wrate RM, Cowen SJ \& Freeman CPL (1995) Body mass index as an estimate of body fat. Int J Eat Disord 18, 91-97.

Heymsfield SB, Allison DB, Wang ZM, Baumgartner RN \& Ross R (1998) Evaluation of total and regional body composition. In Handbook of Obesity, pp. 41-78 [G Bray, C Bouchard and P James, editors]. New York: Marcel Dekker.

Heymsfield SB, Lichtman S, Baumgartner RN, Wang J, Kamen Y, Aliprantis A \& Pierson RN Jr (1990) Body composition of humans: comparison of two improved four-component models that differ in expense, technical complexity, and radiation exposure. Am J Clin Nutr 52, 52-58.

Huang TT, Harris KJ, Lee RE, Nazir N, Born W \& Kaur H (2003) Assessing overweight, obesity, diet, and physical activity in college students. J Am Coll Health 52, 83-86.

Kitano T, Kitano N, Inomoto T \& Futatsuka M (2001) Evaluation of body composition using dual-energy X-ray absorptiometry, skinfold thickness and bioelectrical impedance analysis in Japanese female college students. J Nutr Sci Vitaminol (Tokyo) 47, $122-125$.

Lean ME, Han TS \& Deurenberg P (1996) Predicting body composition by densitometry from simple anthropometric measurements. Am J Clin Nutr 63, 4-14.

Lohman TG (1992) Advances in Body Composition Assessment. Champaign, IL: Human Kinetics Publisher.

Lowry R, Galuska DA, Fulton JE, Wechsler H, Kann L \& Collins JL (2000) Physical activity, food choice, and weight management goals and practices among US college students. Am J Prev Med 18, 18-27.

Luke A, Durazo-Arvizu R, Rotimi C, Prewitt TE, Forrester T, Wilks R, Ogunbiyi OJ, Schoeller DA, McGee D \& Cooper RS (1997) Relation between BMI and body fat in black population samples from Nigeria, Jamaica and the United States. Am J Epidemiol 145, 620-628.
McNeill G, Fowler PA, Maughan RJ, McGaw BA, Fuller MF, Gvozdanovic D \& Gvozdanovic S (1991) Body fat in lean and overweight women estimated by six methods. $\mathrm{Br} \mathrm{J} \mathrm{Nutr}$ 65, 95-103.

Martin A \& De Dios J (1993) Bioestadística para las Ciencias de la Salud (Biostatistic in Health Science). Madrid, Spain: Norma.

Mitsuzono R \& Komiya S (1991) Comparison of methods for estimating percent body fat in distance-runners. Ann Physiol Anthropol 10, 219-227.

National Institutes of Health, National Heart, Lung and Blood Institute (1999) Clinical Guidelines on the Identification, Evaluation, and Treatment of Overweight and Obesity in Adults. The Evidence Report. Bethesda, MD: National Institutes of Health.

Parker L, Reilly JJ, Slater C, Wells JC \& Pitsiladis Y (2003) Validity of six field and laboratory methods for measurement of body composition in boys. Obes Res 11, 852-858.

Sarria A, Garcia-Llop LA, Moreno LA, Fleta J, Morellon MP \& Bueno M (1998) Skinfold thickness measurements are better predictors of body fat percentage than body mass index in male Spanish children and adolescents. Eur J Clin Nutr 52, $573-576$.

SEEDO (1996) Consenso español 1995 para la evaluación de la obesidad y para la realización de estudios epidemiológicos (1995 Spanish consensus for the evaluation of obesity and to carry out epidemiologic studies). Med Clin (Barc) 107, $782-787$.

Servicio Central de Publicaciones del Gobierno Vasco (1994) Encuesta de Nutrición de la Comunidad Autónoma del País Vasco (Nutrition Survey in Autonomous Region of Basque Country). Vitoria-Gasteiz, Spain: Dpto. de Salud.

Siri WE (1961) Body composition from fluid spaces and density: analysis of methods. In Techniques for Measuring Body Composition, pp. 223-244 [J Brozeck and A Henschel, editors]. Washington, DC: National Academy of Sciences.

Smalley KJ, Knerr AN, Kendrick ZV, Colliver JA \& Owen OE (1990) Reassessment of body mass indices. Am J Clin Nutr 52, 405-408.

Taylor RW, Keil D, Gold EJ, Williams SM \& Goulding A (1998) Body mass index, waist girth, and waist-to hip ratio as indexes of total and regional adiposity in women: evaluation using receiver operating characteristic curves. Am J Clin Nutr 67, 44-49.

Treuth MS, Butte NJ, Wong WW \& Ellis KJ (2001) Body composition in prepubertal girls: comparison of six methods. Int $J$ Obes Relat Metab Disord 25, 1352-1359.

Wellens R, Chumlea WC, Guo S, Roche AF, Reo NV \& Siervogel RM (1994) Body composition in white adults by dual-energy X-ray absorptiometry, densitometry, and total body water. Am J Clin Nutr 59, 547-555.

World Health Organization (1995) Physical Status: the Use and Interpretation of Anthropometry. Technical Report Series no. 854. Geneva: WHO.

World Health Organization (1998) Programme of Nutrition, Family and Reproductive Health. Obesity. Preventing and Managing the Global Epidemic. Report of a WHO Consultation on Obesity. Geneva, 3-5 June 1997, Geneva: WHO. 